\title{
Occurrence of Fusarium and major mycotoxins in cereal grains harvested in 2011-2012
}

\section{Występowanie grzybów rodzaju Fusarium oraz głównych mikotoksyn w ziarnie zbóż w latach 2011-2012}

\author{
Magdalena Twarużek, Natalia Grajewska-Wanat, Anna Błajet-Kosicka, Jan Grajewski
}

\section{Summary}

Fusarium, due to its toxic properties, has become the fungus with steadily growing significance in Poland as well as worldwide. It is a major agent of fusariosis of cereal ears, the disease responsible for great economic loses, most commonly occuring in wheat, yet also dangerous for rye and barley. Fusarium contamination of cereal does not only lead to harvest decrease and quality drop but more importantly, as a result of its ability to produce secondary metabolites - mycotoxins, to toxicity of cereal produce. In the analysed samples of wheat, triticale, rye and barley grains harvested in 2011-2012, high levels of Fusarium contamination were detected. However, the products harvested in 2011 showed much higher average contamination with the general number of moulds as well as those of the Fusarium genera. Mycotoxicological analysis revealed that wheat and barley contained the highest amount of mycotoxins, respectively.

Key words: Fusarium, mycotoxins, cereal

\section{Streszczenie}

W ostatnich latach w Polsce, podobnie jak i na świecie, coraz większego znaczenia nabierają grzyby rodzaju Fusarium. Pod względem ekonomicznym, najgroźniejszą i najważniejszą chorobą powodowaną przez grzyby rodzaju Fusarium jest fuzarioza kłosów. Najczęściej występuje na pszenicy, ale jest również zagrożeniem dla pozostałych zbóż ozimych i jarych. Szkodliwość polega nie tylko na zmniejszeniu plonu ziarna i pogorszeniu jakości, ale również na wytwarzaniu przez te grzyby szkodliwych wtórnych metabolitów mikotoksyn. W przeprowadzonych badaniach ziarna: pszenicy, pszenżyta, żyta i jęczmienia, przeprowadzonych w latach 2011 i 2012 , wykryto wysoki poziom skażenia grzybami rodzaju Fusarium. Surowce zbożowe z 2011 roku charakteryzowały się znacznie wyższym średnim skażeniem ogólnej liczby grzybami rodzaju Fusarium. Analiza mikotoksykologiczna wykazała, że szczególnie w pszenicy, a następnie w jęczmieniu, występował wyższy udział mikotoksyn.

Słowa kluczowe: Fusarium, mikotoksyny, zboża

\footnotetext{
Uniwersytet Kazimierza Wielkiego Instytut Biologii Eksperymentalnej Zakład Fizjologii i Toksykologii Chodkiewicza 30, 85-064 Bydgoszcz twarmag@ukw.edu.pl
} 


\section{Wstęp / Introduction}

W ostatnich latach w Polsce, podobnie jak i na świecie, coraz większego znaczenia nabierają grzyby rodzaju Fusarium. Związane jest to głównie z monokulturą upraw, ze zmianami klimatycznymi, które sprzyjają ich rozwojowi oraz wzrostem areału uprawy zbóż, na których powodują fuzariozy. Mogą one porażać rośliny we wszystkich fazach rozwojowych, powodując zgorzel siewek, zgniliznę korzeni, zgorzel podstawy źdźbła lub łodyg, fuzariozę liści, kłosów oraz fuzaryjne więdnięcie roślin (Pląskowska 2010). Jedną z najgroźniejszych i najważniejszych pod względem ekonomicznym chorobą powodowaną przez gatunki grzybów należących do rodzaju Fusarium jest fuzarioza kłosów. Najczęściej występuje na pszenicy, ale jest również groźna dla żyta i jęczmienia oraz pozostałych gatunków zbóż. Szkodliwość polega nie tylko na zmniejszeniu plonu ziarna i pogorszeniu jakości, ale również na wytwarzaniu przez grzyby szkodliwych metabolitów - mikotoksyn. Stanowią one trujące produkty przemiany materii określonych rodzajów grzybów, które wywołują patologiczne zmiany $u$ ludzi i zwierząt. Zagrożenie to wynika $\mathrm{z}$ rakotwórczych, mutagennych, teratogennych, względnie chronicznych właściwości tych toksyn (Grajewski 2006). Na zainfekowanie ziarna zbóż przez Fusarium spp. wpływa - oprócz czynników pogodowych i poziomu odporności żywiciela - agrotechnika, m.in. przygotowanie pola, zmianowanie roślin, nawożenie i stosowanie środków ochrony roślin, a więc technologia produkcji roślinnej może w istotny sposób wpływać na zdrowotność roślin i jakość ziarna (Czaban i wsp. 2011).

Celem pracy była ocena zasiedlenia ziarna: pszenicy, pszenżyta, żyta i jęczmienia przez grzyby pleśniowe rodzaju Fusarium oraz poziom ich wtórnych metabolitów - mikotoksyn polowych oraz dodatkowo głównej toksyny magazynowej - ochratoksyny A.

\section{Materiały i metody / Materials and methods}

Materiał badawczy stanowiło ziarno zbóż przeznaczone na cele spożywcze. Próby surowców: pszenicy $(n=26)$, pszenżyta $(n=13)$, żyta $(n=6)$ oraz jęczmienia $(n=9)$ w latach 2011 i 2012 zostały dostarczone do Laboratorium Badawczego Mikotoksyn Uniwersytetu Kazimierza Wielkiego w Bydgoszczy przez przemysł zbożowomłynarski $\mathrm{z}$ terenów całego kraju, w celu badań kontrolnych. Ogólną liczbę grzybów oznaczono według normy PN ISO 7954 (1999) - z modyfikacją własną posiew na podłoże YGC (yeast glukose chloramphenicol agar), chloramfenikol 100 ppm, inkubacja 5-7 dni w temperaturze $25^{\circ} \mathrm{C}$. Ekstrakcję mikotoksyn przeprowadzono z wykorzystaniem kolumn powinowactwa immunologicznego Ochraprep ${ }^{\circledR}$ (R-Biopharm Rhône Ltd) dla OTA (ochratoksyny A) oraz kolumn Bond Elut ${ }^{\circledR}$ Mycotoxin do analizy DON (deoksyniwalenolu), ZEN (zearalenonu), toksyn T-2 i HT-2. Mikotoksyny oznaczono metodą HPLC (high performance liquid chromatography; Merck-Hitachi, Agilent) $\mathrm{z}$ detekcją fluorescencyjną oraz $\mathrm{z}$ podwójną spektrometrią mas MS/MS (AB Sciex).

\section{Wyniki i dyskusja / Results and discussion}

W pierwszym etapie badań określono liczbowy udział wszystkich pleśni w poszczególnych ziarnach zbóż oraz ilość pleśni rodzaju Fusarium. Dane te przedstawiono w tabeli 1.

Analizując uzyskane wyniki można zauważyć znacząco wyższy poziom skażenia grzybami pleśniowymi, a także Fusarium w roku 2011, dla każdej z przebadanych grup zbóż. Lenc i wsp. (2009) w swoich badaniach również oceniali zasiedlenie ziarniaków przez Fusarium i w zależności od odmian odnotowali wartości porażenia 17,6-41,1\%. Autorzy stwierdzili także, że na procentowy udział grzybów pleśniowych istotny wpływ miał przedplon (w kombinacji po rzepaku izolowali istotnie mniej grzybów, aniżeli z kombinacji po pszenicy). Również Narkiewicz-Jodko i wsp. (2005) przedstawili zróżnicowany stopień porażenia pszenicy ozimej przez grzyby rodzaju Fusarium. Największe nasilenie skażeń (46-81\%) odnotowali w 2001 roku (w porównaniu z latami 2000 i 2002).

Tabela 1. Udział grzybów pleśniowych, w tym Fusarium w analizowanym ziarnie zbóż [jtk/g]

Table 1. The content of moulds, including Fusarium in cereal grains [cfu/g]

\begin{tabular}{|c|c|c|c|c|c|c|c|}
\hline $\begin{array}{l}\text { Rodzaj próby } \\
\text { Sample }\end{array}$ & $\begin{array}{l}\text { Rok } \\
\text { Year }\end{array}$ & $\begin{array}{c}\text { Liczba } \\
\text { prób } \\
\text { No. } \\
\text { of samples }\end{array}$ & $\begin{array}{l}\text { Średnia ogólna } \\
\text { liczba pleśni } \\
\text { Average amount } \\
\text { of moulds }\end{array}$ & $\begin{array}{l}\text { Średnia ilość } \\
\text { Fusarium } \\
\text { Average amount } \\
\text { of Fusarium }\end{array}$ & $\begin{array}{c}\text { Średni \% udziału } \\
\text { Fusarium } \\
\text { Average \% } \\
\text { Fusarium share }\end{array}$ & $\begin{array}{l}\text { Maksimum } \\
\text { Maximum } \\
\text { value }\end{array}$ & $\begin{array}{l}\text { Minimum } \\
\text { Minimum } \\
\text { value }\end{array}$ \\
\hline \multirow{2}{*}{$\begin{array}{l}\text { Pszenica } \\
\text { Wheat }\end{array}$} & 2011 & 13 & $12804 \mathrm{~K}$ & $2078 \mathrm{~K}$ & 16 & $66 \%$ & $1 \%$ \\
\hline & 2012 & 13 & $3617 \mathrm{~K}$ & $529 \mathrm{~K}$ & 15 & $58 \%$ & $2 \%$ \\
\hline \multirow{2}{*}{$\begin{array}{l}\text { Pszenżyto } \\
\text { Triticale }\end{array}$} & 2011 & 6 & $78758 \mathrm{~K}$ & $18702 \mathrm{~K}$ & 24 & $46 \%$ & $6 \%$ \\
\hline & 2012 & 7 & $7714 \mathrm{~K}$ & $893 \mathrm{~K}$ & 12 & $36 \%$ & $7 \%$ \\
\hline \multirow{2}{*}{$\begin{array}{l}\text { Żyto } \\
\text { Rye }\end{array}$} & 2011 & 3 & $21717 \mathrm{~K}$ & $10800 \mathrm{~K}$ & 50 & $76 \%$ & $14 \%$ \\
\hline & 2012 & 3 & $2291 \mathrm{~K}$ & $129 \mathrm{~K}$ & 6 & $7 \%$ & $1 \%$ \\
\hline \multirow{2}{*}{$\begin{array}{l}\text { Jęczmień } \\
\text { Barley }\end{array}$} & 2011 & 4 & $29621 \mathrm{~K}$ & $7533 \mathrm{~K}$ & 25 & $51 \%$ & $2 \%$ \\
\hline & 2012 & 5 & $14345 \mathrm{~K}$ & $2703 \mathrm{~K}$ & 19 & $49 \%$ & $5 \%$ \\
\hline
\end{tabular}

$\mathrm{K}$ - kolonia - colony 
W badaniach własnych najwyższym stopniem porażenia grzybami rodzaju Fusarium charakteryzowało się ziarno pszenżyta w roku 2011, które w 1 g zawierało ponad 18 tys. kolonii grzybów. Góral (2007, 2009) opublikował zbliżone wartości dla tego ziarna, a średni procentowy udział Fusarium wyniósł odpowiednio 24,5 i 23,3\%. Autor wykazał również istotne zróżnicowanie odporności rodów hodowanego pszenżyta na fuzariozę kłosów oraz ustalił współczynnik korelacji między fuzariozą kłosów a uszkodzeniem ziarniaków (16\%).

Oceniane ziarno żyta było silniej zasiedlone przez grzyby ze zbiorów w 2011 roku, a grzyby rodzaju Fusarium stanowiły prawie połowę średniego udziału wszystkich pleśni.

Przeprowadzone analizy mikologiczne jęczmienia wykazały także liczne zasiedlenie przez grzyby. Wiewióra (2010) zidentyfikowała również wiele gatunków grzybów występujących na ziarnie jęczmienia. W czasie obserwacji polowych odnotowała występowanie objawów chorobowych, których sprawcami były patogeny przenoszone $\mathrm{z}$ materiałem siewnym (plamistość siatkowata, fuzarioza kłosów, czy inne plamistości liści).

W kolejnym etapie badań dokonano analizy mikotoksykologicznej. Wyniki skażenia mikotoksynami prób pszenicy przedstawiono w tabeli 2 .

Wszystkie próby ziarna pszenicy (niezależnie od roku) charakteryzowały się obecnością DON i ZEN.
Uzyskane wyniki mikotoksykologiczne potwierdziły wyższy poziom ZEN oraz OTA $w$ ziarnie pszenicy pozyskanym w 2011 roku. Udział DON w obu badanych latach był porównywalny. Toksyny T-2 i HT-2 w wyższym stężeniu występowały w surowcu z 2012 roku. Średnia zawartość DON była najwyższa z pozostałych badanych mikotoksyn. Wyniki te potwierdzają sugestię Sadowskiego i wsp. (2009), którzy podaja, że DON jest najczęściej występującą mikotoksyną w ziarnie zbóż na terenie Polski. Wynika to $\mathrm{z}$ faktu, że w naszych warunkach głównym producentem tej toksyny jest Fusarium culmorum. Należy zaznaczyć, że maksymalne stężenie badanej mikotoksyny w dwóch próbach pszenicy, przeznaczonej do bezpośredniej konsumpcji (1154 i 1025 ppb), znacznie przekroczyło dopuszczalną zawartość określoną w Rozporządzeniu (2007) - czyli 750 ppb, natomiast w przypadku innych dwóch prób poziom ten był bliski górnej dopuszczalnej granicy (728 i 720 ppb). Sadowski i wsp. (2009) analizując fuzariozę kłosów i zawartość DON w ziarnie, wykazali wyraźna zależność między nasileniem objawów chorobowych a zawartością tej toksyny. W przypadku ZEN dla pszenicy, dwie próby przekroczyły przyjęty dopuszczalny poziom, który wynosi $100 \mathrm{ppb}$. Oznaczone ilości to: 115 i 109 ppb. Stanisławczyk i wsp. (2010) analizując występowanie mikotoksyn w ziarnie zbóż, wykryli przekroczenie dopuszczalnego poziomu w przypadku DON (784 ppb), natomiast dla ZEN poziomy nie były tak wysokie, jak w badaniach własnych.

Tabela 2. Analiza mikotoksykologiczna prób ziarna pszenicy z lat 2011-2012 [ppb]

Table 2. Mycotoxicological analysis of wheat grain samples harvested in 2011-2012 [ppb]

\begin{tabular}{|c|c|c|c|c|c|c|c|}
\hline & & & DON & ZEN & $\mathrm{T}-2$ & HT-2 & OTA \\
\hline \multirow{12}{*}{ 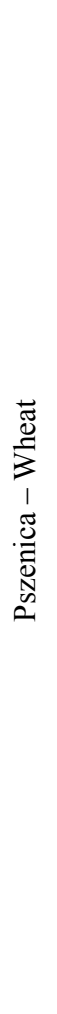 } & \multirow{6}{*}{2011} & $\begin{array}{l}\text { Liczba prób/pozytywnych } \\
\text { No. of samples/positive samples }\end{array}$ & $11 / 11$ & $9 / 9$ & $9 / 4$ & $9 / 5$ & $6 / 1$ \\
\hline & & $\begin{array}{l}\% \text { pozytywnych } \\
\% \text { positive samples }\end{array}$ & $100 \%$ & $100 \%$ & $44 \%$ & $56 \%$ & $17 \%$ \\
\hline & & $\begin{array}{l}\text { średnia } \\
\text { average }\end{array}$ & 327 & 41,35 & 0,62 & 2,25 & 0,56 \\
\hline & & $\begin{array}{l}\text { maksimum } \\
\text { maximum value }\end{array}$ & 1154 & 115 & 2,31 & 5 & 3,33 \\
\hline & & $\begin{array}{l}\text { minimum } \\
\text { minimum value }\end{array}$ & $<3$ & $<0,2$ & nw & nw & nw \\
\hline & & $\begin{array}{l}\text { mediana } \\
\text { median }\end{array}$ & 119 & 54,1 & nw & 2 & nw \\
\hline & \multirow{6}{*}{2012} & $\begin{array}{l}\text { liczba prób/pozytywnych } \\
\text { no. of samples/positive samples }\end{array}$ & $12 / 12$ & $10 / 10$ & $10 / 9$ & $10 / 9$ & $3 / 1$ \\
\hline & & $\begin{array}{l}\% \text { pozytywnych } \\
\% \text { positive samples }\end{array}$ & $100 \%$ & $100 \%$ & $90 \%$ & $90 \%$ & $33 \%$ \\
\hline & & $\begin{array}{l}\text { średnia } \\
\text { average }\end{array}$ & 391 & 15 & 1,09 & 8,63 & 0,16 \\
\hline & & $\begin{array}{l}\text { maksimum } \\
\text { maximum value }\end{array}$ & 1025 & 109 & 1,92 & 18,7 & 0,49 \\
\hline & & $\begin{array}{l}\text { minimum } \\
\text { minimum value }\end{array}$ & 11,6 & 0,23 & nw & nw & nw \\
\hline & & $\begin{array}{l}\text { mediana } \\
\text { median }\end{array}$ & 247,5 & 2,9 & 1,06 & 7,41 & nw \\
\hline
\end{tabular}

nw - nie wykryto - not detected

DON - deoksyniwalenol - deoxynivalenol; ZEN - zearalenon - zearalenone; T-2 - toksyna T-2 - T-2 toxin; HT-2 - toksyna HT-2 - HT-2 toxin;

OTA - ochratoksyna A - ochratoxin A 
Analiza stężenia OTA nie wykazała przekroczenia dopuszczalnych poziomów (5 ppb) - Rozporządzenie (2006). Spośród 9 badanych prób, OTA wykryto w dwóch - $\mathrm{z}$ najwyższym poziomem $3,33 \mathrm{ppb}$. Wyniki te potwierdzają badania Pokrzywy i wsp. (2007), którzy nie zaobserwowali przekroczeń normy OTA w ziarnie pszenicy i biopszenicy. Przypadki wyższych poziomów skażeń przez OTA stwierdzono w badaniach mikotoksykologicznych surowców paszowych (Grajewski i wsp. 2012a).

Udział mikotoksyn w pozostałych zbożach był znacznie niższy niż w przypadku pszenicy. We większości prób nie wykryto obecności szkodliwych metabolitów, natomiast oznaczone ilości kształtowały się na poziomie znacząco niższym niż dopuszczalne zawartości. Poziom mikotoksyn $\mathrm{w}$ ocenianym pszenżycie był niższy niż w pszenicy. Także procent prób pozytywnych odbiegał od pszenicy. Jedynie w jednej próbie z 2011 roku oznaczono ponad 8 ppb trichoteceny toksyny $\mathrm{T}-2$. W tabelach $3-5$ przedstawiono analizę mikotoksykologiczną pozostałych prób zbóż.

Solarska i wsp. (2010) w ziarniakach pszenżyta ozimego wykryli DON w 46,1\% przeanalizowanych prób. Pozostałych mikotoksyn (aflatoksyn, OTA, T-2 i ZEN) nie zaobserwowali. W przeprowadzonych badaniach własnych najczęściej wykrywano DON (33\% w roku 2011 i 29\% w roku 2012), natomiast ZEN, T-2, HT-2 wykrywano na tych samych poziomach (w 17\% prób w roku 2011 i 14\% prób w roku 2012).
W ziarnie żyta mimo wysokiego udziału grzybów pleśniowych rodzaju Fusarium (szczególnie w roku 2011), nie powstało dużo wtórnych metabolitów. DON wykryto zaledwie $\mathrm{W}$ dwóch próbach $\mathrm{z}$ maksymalnym poziomem w roku $2011-7,53$ ppb i 23,1 ppb w roku 2012, natomiast obecności pozostałych mikotoksyn nie odnotowano. $\mathrm{W}$ innych badaniach własnych oceniających próby żyta w latach 2009-2010, DON wykryto w 37\% prób z maksymalnym stężeniem $140 \mathrm{ppb}$, natomiast ZEN - wykryty został w 46\% prób z najwyższym stężeniem 72,4 ppb (Grajewski i wsp. 2012b).

$\mathrm{W}$ przeprowadzonych badaniach ziarna jęczmienia najczęściej wykrywano DON w 75\% w 2011 roku i 60\% w 2012 roku (z najwyższymi stężeniami odpowiednio 346 i 93,2 ppb). ZEN, T-2 i HT-2 wykryto w 25\% prób z 2011 roku i 20\% prób z roku 2012. Mazurkiewicz i wsp. (2008) przeanalizowali 24 próby jęczmienia jarego, w którym zaobserwowali w najwyższym stopniu zanieczyszczenie DON. Pozostałe mikotoksyny stwierdzili w nieznacznych ilościach, co potwierdzają uzyskane wyniki badań własnych. Korbas i wsp. (2009) w przeprowadzonej analizie skażeń jęczmienia wykazali już obecność DON i ZEN. Zawartość DON w żadnej próbie nie była wyższa niż dopuszczalna norma, natomiast w części prób poziom wykrytego ZEN przekraczał dopuszczalną zawartość (75 ppb).

Tabela 3. Analiza mikotoksykologiczna prób ziarna pszenżyta w latach 2011-2012 [ppb]

Table 3. Mycotoxicological analysis of triticale grain samples harvested in 2011-2012 [ppb]

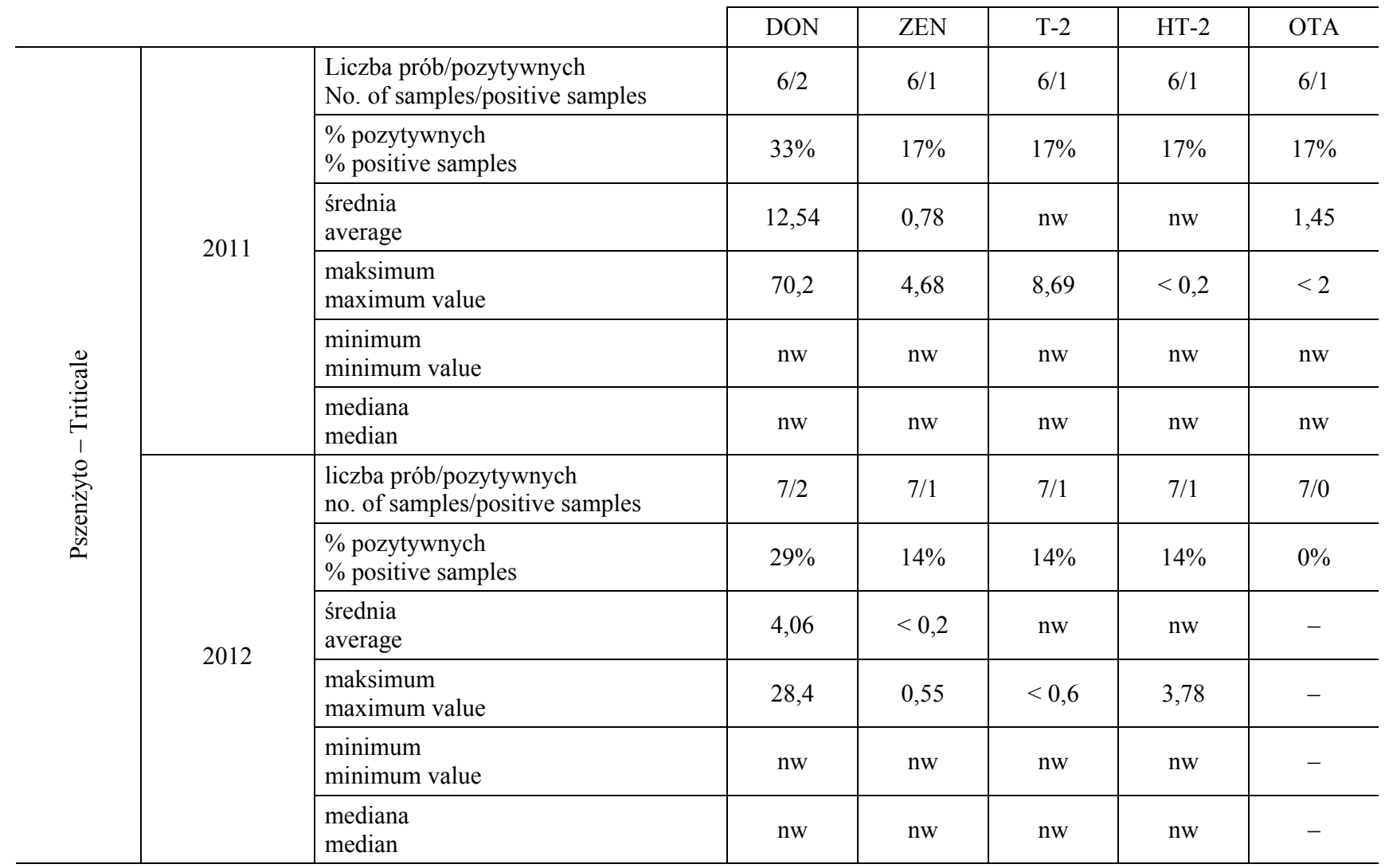

nw - nie wykryto - not detected

DON - deoksyniwalenol - deoxynivalenol; ZEN - zearalenon - zearalenone; T-2 - toksyna T-2 - T-2 toxin; HT-2 - toksyna HT-2 - HT-2 toxin; OTA - ochratoksyna A - ochratoxin A 
Tabela 4. Analiza mikotoksykologiczna prób ziarna żyta w latach 2011-2012 [ppb]

Table 4. Mycotoxicological analysis of rye grain samples harvested in 2011-2012 [ppb]

\begin{tabular}{|c|c|c|c|c|c|c|c|}
\hline & & & & & & & \\
\hline & & & DON & ZEN & $\mathrm{T}-2$ & HT-2 & OTA \\
\hline \multirow{12}{*}{ 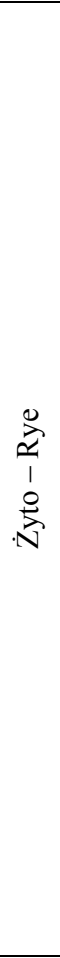 } & \multirow{6}{*}{2011} & $\begin{array}{l}\text { Liczba prób/pozytywnych } \\
\text { No. of samples/positive samples }\end{array}$ & $3 / 1$ & $3 / 0$ & $3 / 0$ & $3 / 0$ & $3 / 0$ \\
\hline & & $\begin{array}{l}\text { \% pozytywnych } \\
\% \text { positive samples }\end{array}$ & $33 \%$ & $0 \%$ & $0 \%$ & $0 \%$ & $0 \%$ \\
\hline & & $\begin{array}{l}\text { średnia } \\
\text { average }\end{array}$ & 2,51 & - & - & - & - \\
\hline & & $\begin{array}{l}\text { maksimum } \\
\text { maximum value }\end{array}$ & 7,53 & - & - & - & - \\
\hline & & $\begin{array}{l}\text { minimum } \\
\text { minimum value }\end{array}$ & nw & - & - & - & - \\
\hline & & $\begin{array}{l}\text { mediana } \\
\text { median }\end{array}$ & nw & - & - & - & - \\
\hline & \multirow{6}{*}{2012} & $\begin{array}{l}\text { liczba prób/pozytywnych } \\
\text { no. of samples/positive samples }\end{array}$ & $3 / 1$ & $3 / 0$ & $3 / 0$ & $3 / 0$ & $3 / 0$ \\
\hline & & $\begin{array}{l}\text { \% pozytywnych } \\
\% \text { positive samples }\end{array}$ & $33 \%$ & $0 \%$ & $0 \%$ & $0 \%$ & $0 \%$ \\
\hline & & $\begin{array}{l}\text { średnia } \\
\text { average }\end{array}$ & 7,7 & - & - & - & - \\
\hline & & $\begin{array}{l}\text { maksimum } \\
\text { maximum value }\end{array}$ & 23,1 & - & - & - & - \\
\hline & & $\begin{array}{l}\text { minimum } \\
\text { minimum value }\end{array}$ & nw & - & - & - & - \\
\hline & & $\begin{array}{l}\text { mediana } \\
\text { median }\end{array}$ & nw & - & - & - & - \\
\hline
\end{tabular}

nw - nie wykryto - not detected

DON - deoksyniwalenol - deoxynivalenol; ZEN - zearalenon - zearalenone; T-2 - toksyna T-2 - T-2 toxin; HT-2 - toksyna HT-2 - HT-2 toxin; OTA - ochratoksyna A - ochratoxin A

Tabela 5. Analiza mikotoksykologiczna prób ziarna jęczmienia w latach 2011-2012 [ppb]

Table 5. Mycotoxicological analysis of barley grain samples harvested in 2011-2012 [ppb]

\begin{tabular}{|c|c|c|c|c|c|c|c|}
\hline & & & & & & & \\
\hline & & & DON & ZEN & $\mathrm{T}-2$ & HT-2 & OTA \\
\hline \multirow{12}{*}{ 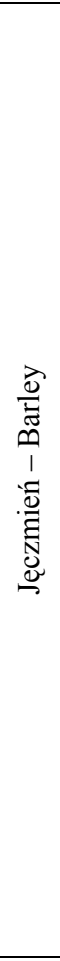 } & \multirow{6}{*}{2011} & $\begin{array}{l}\text { Liczba prób/pozytywnych } \\
\text { No. of samples/positive samples }\end{array}$ & $4 / 3$ & $4 / 1$ & $4 / 1$ & $4 / 1$ & $4 / 0$ \\
\hline & & $\begin{array}{l}\text { \% pozytywnych } \\
\% \text { positive samples }\end{array}$ & $75 \%$ & $25 \%$ & $25 \%$ & $25 \%$ & $0 \%$ \\
\hline & & $\begin{array}{l}\text { średnia } \\
\text { average }\end{array}$ & 88,94 & 10,15 & nw & nw & - \\
\hline & & $\begin{array}{l}\text { maksimum } \\
\text { maximum value }\end{array}$ & 346 & 40,6 & $<0,6$ & $<2$ & - \\
\hline & & $\begin{array}{l}\text { minimum } \\
\text { minimum value }\end{array}$ & nw & nw & nw & nw & - \\
\hline & & $\begin{array}{l}\text { mediana } \\
\text { median }\end{array}$ & 5,02 & nw & nw & nw & - \\
\hline & \multirow{6}{*}{2012} & $\begin{array}{l}\text { liczba prób/pozytywnych } \\
\text { no. of samples/positive samples }\end{array}$ & $5 / 3$ & $5 / 1$ & $5 / 1$ & $5 / 1$ & $5 / 0$ \\
\hline & & $\begin{array}{l}\text { \% pozytywnych } \\
\% \text { positive samples }\end{array}$ & $60 \%$ & $20 \%$ & $20 \%$ & $20 \%$ & $0 \%$ \\
\hline & & $\begin{array}{l}\text { Średnia } \\
\text { average }\end{array}$ & 29,32 & nw & $<0,6$ & 2,58 & - \\
\hline & & $\begin{array}{l}\text { maksimum } \\
\text { maximum value }\end{array}$ & 93,2 & 0,25 & 2,62 & 12,9 & - \\
\hline & & $\begin{array}{l}\text { minimum } \\
\text { minimum value }\end{array}$ & nw & nw & nw & nw & - \\
\hline & & $\begin{array}{l}\text { mediana } \\
\text { median }\end{array}$ & 20 & nw & nw & nw & - \\
\hline
\end{tabular}

nw - nie wykryto - not detected

DON - deoksyniwalenol - deoxynivalenol; ZEN - zearalenon - zearalenone; T-2 - toksyna T-2 - T-2 toxin; HT-2 - toksyna HT-2 - HT-2 toxin; OTA - ochratoksyna A - ochratoxin A 


\section{Wnioski / Conclusions}

1. Uzyskane wyniki analiz potwierdzają problem występowania grzybów powodujących pleśnienie ziarna i ich metabolitów w ziarnach zbóż konsumpcyjnych oraz problem stanu higienicznego tych surowców. Stopień zanieczyszczenia zależał od rodzaju badanej próby oraz roku jej pobrania.

2. W roku 2011 średnia ogólna liczba grzybów, jak również średnia ilość grzybów rodzaju Fusarium, była znacznie większa niż w roku 2012.

3. Najczęściej wykrywaną mikotoksyną był DON, kolejno w ziarnie pszenicy, jęczmienia, żyta i pszenżyta, udział pozostałych mikotoksyn był znacząco niższy.
Badania finansowane $\mathrm{w}$ ramach projektu międzynarodowego niewspółfinansowanego o numerze decyzji 761/NAUSTRIA/2010/0.

\section{Podziękowania / Acknowledgements}

Autorzy dziękują mgr Ewelinie Soszczyńskiej oraz mgr Robertowi Kosickiemu za pomoc w wykonaniu badań.

\section{Literatura / References}

Czaban J., Wróblewska B., Sułek A., Podolska G. 2011. Wpływ różnych technologii produkcji pszenicy ozimej na zasiedlenie jej ziarna przez grzyby z rodzaju Fusarium. Pol. J. Agron. 5: 11-20.

Góral T. 2007. Ocena odporności rodów pszenicy i pszenżyta na fuzariozę kłosów, pleśń śniegową i rdzę brunatną w Radzikowie w 2006 roku. Biul. IHAR 246: 31-44.

Góral T. 2009. Odporność odmian pszenżyta ozimego na fuzariozę kłosów powodowaną przez grzyb Fusarium culmorum. Biul. IHAR 254: $41-50$

Grajewski J. (red.). 2006. Mikotoksyny i grzyby pleśniowe zagrożenia dla ludzi i zwierząt. Wyd. UKW, Bydgoszcz, 202 ss.

Grajewski J., Błajet-Kosicka A., Twarużek M., Kosicki R. 2012a. Occurrence of mycotoxins in Polish animal feed in years $2006-2009$. J. Animal Physiol. Animal Nutrition 96 (5): 870-877.

Grajewski J., Błajet-Kosicka A., Twarużek M., Kosicki R., Sibiorowska E. 2012b. Mycotoxicological evaluation of rye and its products. p. 65. W: Materiały Konferencji „34th Mycotoxin Workshop”. Niemcy, Braunschweig, 14-16 maja 2012, 141 pp.

Korbas M., Horoszkiewicz-Janka J., Krawczyk R., Pieczul K. 2009. Zawartość mikotoksyn w ziarnie jęczmienia jarego uprawianego w systemie ekologicznym. [Content of mycotoxins in spring barley grain cultivated in ecological system]. Prog. Plant Prot./Post. Ochr. Roślin 49 (3): 1561-1564.

Lenc L., Wyczling D., Sadowski Cz. 2009. Zasiedlenie ziarna pszenicy ozimej przez grzyby rodzaju Fusarium w zależności od przedplonu, uprawianej odmiany i stosowanych fungicydów. Ochrona Środowiska i Zasobów Naturalnych 41: 563-571.

Mazurkiewicz J., Solarska E., Muszyńska M., Kuzdraliński A. 2008. Występowanie trichotecenów fuzaryjnych w jęczmieniu jarym z systemów produkcji ekologicznej i konwencjonalnej. [The occurrence of Fusarium trichothecenes in spring barley from organic and conventional production systems]. Prog. Plant Prot./Post. Ochr. Roślin 48 (2): 426-429.

Narkiewicz-Jodko M., Gil Z., Urban M. 2005. Porażenie podstawy źdźbła pszenicy ozimej przez Fusarium spp. - przyczyny i skutki. Acta Agrobot. 58 (2): 319-328.

Pląskowska E. 2010. Charakterystyka i taksonomia grzybów z rodzaju Fusarium. Mikologia Lekarska 17 (3): $172-176$.

PN ISO 7954. 1999. Mikrobiologia - Ogólne zasady oznaczania drożdży i pleśni - Metoda płytkowa w $25^{\circ} \mathrm{C}$. PKN, Warszawa.

Pokrzywa P., Cieślik E., Topolska K. 2007. Ocena zawartości mikotoksyn w wybranych produktach spożywczych. Żywność. Nauka. Technologia. Jakość 3 (52): 139-146.

Rozporządzenie Komisji (WE) nr 1881/2006 z dnia 20 grudnia 2006 r. ustalające najwyższe dopuszczalne poziomy niektórych zanieczyszczeń w środkach spożywczych (Dz. U. Nr L 364): 5-24.

Rozporządzenie Komisji (WE) nr 1126/2007 z dnia 28 września 2007 r. zmieniające Rozporządzenie (WE) nr 1881/2006 ustalające najwyższe dopuszczalne poziomy niektórych zanieczyszczeń w środkach spożywczych w odniesieniu do toksyn Fusarium w kukurydzy i produktach z kukurydzy. (Dz. Urz. WE L 255): 14-17.

Sadowski Cz., Lenc L., Lemańczyk G., Pańka D. 2009. Występowanie fuzariozy kłosów pszenicy ozimej (Fusarium culmorum chemotyp DON) w zależności od programu ochrony. [Occurrence of Fusarium head blight of winter wheat (Fusarium culmorum DON chemotype) in dependence on fungicidal protection programs]. Prog. Plant Prot./Post. Ochr. Roślin 49 (3): 1344-1348.

Solarska E., Kuzdraliński A., Wójcik W., Targoński Z. 2010. Mycotoxins in winter triticale cultivated in organic production system. J. Res. Appl. Agric. Engin. 55 (4): 102-107.

Stanisławczyk R., Rudy M., Świątek B. 2010. Występowanie mikotoksyn w zbożach i przetworach zbożowych znajdujących się w placówkach handlowych województwa podkarpackiego. Żywność. Nauka. Technologia. Jakość 6 (73): 58-66.

Wiewióra B. 2010. Wpływ zdrowotności materiału siewnego jęczmienia jarego na występowanie chorób na roślinach oraz wartość siewną zebranego ziarna. Biul. IHAR 275/258: 3-16. 